\title{
Acute pulmonary hemorrhage after dislocation of transcatheter aortic valve prosthesis
}

\author{
leva Norkiene ${ }^{1}$, Robertas Samalavicius ${ }^{2}$, Kestutis Rucinskas² ${ }^{2}$ Audrius Aidietis², Pranas Serpytis ${ }^{2}$ \\ ${ }^{1}$ Clinic of Anaesthesiology and Reanimatology, Faculty of Medicine, Vilnius University, Vilnius, Lithuania \\ ${ }^{2}$ Centre of Cardiology and Angiology, Vilnius University, Vilnius, Lithuania
}

Kardiochirurgia i Torakochirurgia Polska 2017; 14 (3): 203-205

Transcatheter aortic valve implantation (TAVI) has been increasingly used as a preferred treatment for severe symptomatic aortic stenosis in inoperable and high surgical risk patients. The choice between the surgical or TAVI approach is made based on estimated surgical risk and comorbidities of the individual patient [1]. Contemporary imaging techniques and advances in valve technology resulted in a decrease of complications and improved overall outcomes. The role of TAVI is expanding - newer indications for its use are under research [2]. There is growing interest in the application of TAVI in lower surgical risk patients or in patients with anatomical difficulties [3]. Recent reports confirm the trend of transcatheter valve replacement in patients who are at low or intermediate risk [4]. The conventional surgical approach is not superior to TAVI in intermediate risk patients. Moreover, less invasive procedures result in lower risk of major postoperative complications and more rapid early recovery, which result in shorter durations of stay in the intensive care unit (ICU) and hospital. We present a case of unsuccessful TAVI complicated with acute severe bronchial bleeding in a patient with aortic coarctation.

A 73-year-old woman with worsening shortness of breath (New York Heart Association class III) due to aortic valve lesions was referred for aortic valve replacement. Prior to admission she underwent interposition graft replacement for aortic coarctation in her childhood. Baseline transthoracic echocardiography reported a calcified aortic valve with an aortic valve area of $0.7 \mathrm{~cm}^{2}$, mean pressure gradient of $40.9 \mathrm{~mm} \mathrm{Hg}$ alongside moderately impaired left ventricular ejection fraction of $30 \%$ and moderate pulmonary hypertension.

Multislice computed tomography (MSCT) and cardiac catheterization angiography revealed normal coronary arteries; diameters of the aortic annulus and ascending aorta at the sinotubular junction were 25 and $33 \mathrm{~mm}$, respectively. Images demonstrated postcoarctation repair appearance of the aortic arch with the diameter of $25 \mathrm{~mm}$ and evidence of re-coarctation narrowing and kinking in the proximal de- scending aorta up to $20 \mathrm{~mm}$. Diameter of the descending aorta of was $26 \mathrm{~mm}$ with normal appearance of suprarenal and infrarenal segments.

Patients' logistic European System for Cardiac Operative Risk Evaluation (EuroSCORE II) was 5.78\% and Society of Thoracic Surgeons (STS)-predicted mortality was $2.3 \%$. The patient refused to undergo conventional surgery. She was advised to undergo the surgical replacement of the aortic valve, but insisted on a non-invasive approach, or otherwise refused surgery at all. After multidisciplinary evaluation TAVI as an alternative strategy was suggested and the risks explained to the patient. The patient consented and accepted the risks of intervention.

The TAVI procedure was performed under general anesthesia. The Medtronic Core Valve nitinolporcine prosthesis, with full expansion of $26 \mathrm{~mm}$ in diameter, corresponding to the aortic annulus diameter, was selected. The interventional cardiologist chose the right femoral artery approach for the procedure. Once the pre-implantation balloon valvuloplasty with a $20 \times 40 \mathrm{~mm}$ Amplatzer (St Jude Medical, MN, USA) sizing balloon was successful, an $18 \mathrm{Fr}(6 \mathrm{~mm})$ sheath was used to introduce the valve prosthesis. Femoral vein access was used as well for HF pacing. After positioning the valve under fluoroscopic and TOE guidance, aortic insufficiency was detected. All attempts to reposition the valve were unsuccessful and ended up with a dislocated and stuck CoreValve in the descending aorta (Fig. 1). A pigtail catheter inserted through the brachial artery was used to verify that the valve was not occluding the carotid or subclavian arteries. Post-procedural TOE showed valve insufficiency of second degree.

After approximately two hours from arrival at the ICU, while the patient was still intubated, sudden massive hemoptysis developed. Fiberoptic bronchoscopy with continuous suction and saline lavage were necessary to localize the source of bleeding, which appeared to be left main bronchus. Fluid replacement, inotropic agents, coagulation factors and hemotransfusion were used to stabilize the pa-

Address for correspondence: leva Norkiene MD, PhD, Clinic of Anaesthesiology and Reanimatology, Faculty of Medicine, Vilnius University, Santariskiu 2, 08448 Vilnius, Lithuania, phone: +37 061251582, e-mail: ievanork@gmail.com

Received: 13.12.2016, accepted: 29.05.2017. 

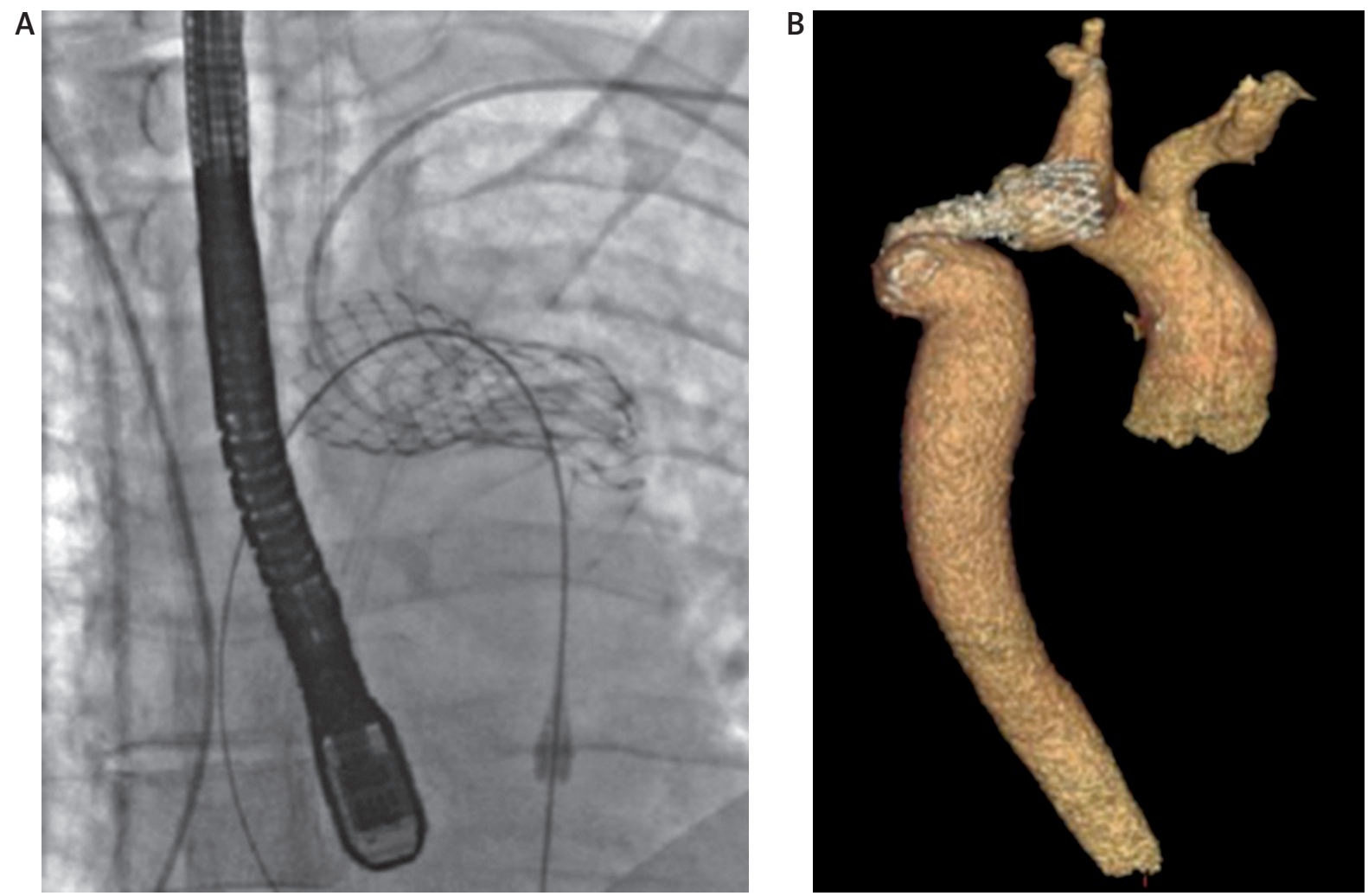

Fig. 1. A - Cardiac catheterization angiography showing aortic valve implantation procedure and the misplacement of percutaneous valve in descending aorta. B - Three-dimensional reconstructed sagittal view of the aortic arch and misplaced TAVI in descending aorta

tient. After a few attempts to stop the bleeding with an intrabronchial infusion of saline with epinephrine, it was decided to perform endobronchial tamponade. A balloon catheter was used to obturate the left main bronchus proximally to the bleeding site. Fiberoptic bronchoscopy was continued to clear the airways of blood and clots and verify the cessation of bleeding.

After the patient's condition became stable, chest computed tomography (CT) angiography was performed and revealed no contrast extravasation or signs of pulmonary embolization.

An attempt to remove the balloon catheter ended with repeat bleeding, and a polyurethane foam obturator was used to occlude the upper left bronchus. A few days later the obturator was removed, with no more signs of obvious bleeding and no indication for other treatments. During hospitalization more control bronchoscopies were undertaken and showed no further hemorrhages. The patient was extubated and discharged from the ICU.

Transcatheter valve implantation performed in appropriately selected patients can offer a substantial improvement in patients with high estimated surgical risk. New generation valves and delivery systems, alongside successful clinical reports, are expanding indications for transcatheter aortic valve implantation. The TAVI has been demonstrated to be a feasible option in a wider population with potential contraindications for a transvascular approach $[5,6]$. We report a case of unsuccessful TAVI implantation in a patient with coarctation and multidirectional kinking and narrowing of the aorta. Angling of the aorta between the descending part and aortic arch has been demonstrated as a predisposing factor for perforation of the aorta by the TAVI delivery system [7]. Recent reports have demonstrated that the TAVI procedure is feasible in patients with narrowing of the aortic diameter $[8,9]$, even in cases of unexpected pseudocoarctation [10]. However, our case report suggests that operators should be extremely cautious when selecting the insertion site of the prosthesis. Introducing the delivery sheath might damage the fragile aortic wall in a torturous vessel. Therefore it is always worth considering that patients who have severe peripheral vascular disease or aortic structure abnormalities might be only amenable to treatment with the direct aortic or transapical TAVI approach through mini-thoracotomy. Planning access for TAVI multi-imaging and evaluation of the whole length of the aorta is highly recommended; it can give us knowledge on vessel calcification and tortuosity. Before intervention we should be aware that aortic coarctation might be associated with anatomic abnormalities of head and neck vessels.

In our case, despite the fact that angiography failed to reveal the potential bleeding site, we assume that extravasation to the left main bronchus was related to damage of the fragile aortic wall at the coarctation site, while repositioning the valve. Bronchial bleeding was a dangerous complication, which ended successfully after isolation of the left main bronchus. To our knowledge it is the first time such a complication has been mentioned after TAVI. 
A multidisciplinary team including a cardiac surgeon and an interventional cardiologist should determine the choice of treatment for aortic valve stenosis in intermediate surgical risk patients. Operators should pay thorough attention and be prepared for challenging anatomic characteristics of the individual patient.

Advanced aortic pathology with severe aortic regurgitation remains a therapeutic clinical dilemma. Before considering TAVI as a treatment option in patients with severely impaired aortic anatomy, tactics, risks and benefits of the procedure should be thoroughly weighed.

\section{Disclosure}

Authors report no conflict of interest.

\section{References}

1. Nishimura RA, Otto CM, Bonow RO, Carabello BA, Erwin JP, Guyton RA, O'Gara PT, Ruiz CE, Skubas NJ, Sorajjja P, Sundt III TM, Thomas JD. 2014 AHA/ ACC guideline for the management of patients with valvular heart disease: a report of the American College of Cardiology/American Heart Association Task Force on Practice Guidelines. J Am Coll Cardiol 2014; 63: e57.

2. Leon MB, Smith CR, Mack MJ, Makkar RR, Svensson LG, Kodali SK, Thourani VH, Tuzcu EM, Miller DC, Herrmann HC, Doshi D, Cohen DJ, Pichard AD, Kapadia S, Dewey T, Babaliaros V, Szeto WY, Williams MR, Kereiakes D, Zajarias A, Greason KL, Whisenant BK, Hodson RW, Moses JW, Trento A, Brown DL, Fearon WF, Pibarot P, Hahn RT, Jaber WA, Anderson WN, Alu MC,
Webb JG; PARTNER 2 Investigators. Transcatheter or surgical aortic-valve replacement in intermediate-risk patients. N Engl J Med 2016; 374: 1609.

3. O'Sullivan CJ, Wenaweser P. Optimizing clinical outcomes of transcatheter aortic valve implantation patients with comorbidities Expert Rev Cardiovasc Ther 2015; 13: 1419-1432.

4. Yousef A, Froeschl M, Hibbert B, Burwash IG, Labinaz M. Transcatheter aortic valve implantation: current and evolving indications. Can J Cardiol 2011; 32 266-269.

5. Bax J, Delgado V, Bapat V, Baumgartner H, Collet JP, Erbel R, Hamm C, Kappetein AP, Leipsic J, Leon MB, MacCarthy P, Piazza N, Pibarot P, Roberts WC, Rodés-Cabau J, Serruys PW, Thomas M, Vahanian A, Webb J, Zamorano JL, Windecker S. Open issues in transcatheter aortic valve implantation. Part 1: patient selection and treatment strategy for transcatheter aortic valve implantation. Eur Heart J 2014; 35: 2627-2638.

6. Mack MJ, Holmes DR, Webb J, Cribier A, Kodali SK, Williams MR, Leon MB. Patient selection for transcatheter aortic valve replacement. J Am Coll Cardiol 2013; 62: S1-S10.

7. Aminian A, Lalmand J, El Nakadi B. Perforation of the descending thoracic aorta during transcatheter aortic valve implantation (TAVI): an unexpected and dramatic procedural complication. Catheter Cardiovasc Interv 2011; 77: 1076-1078.

8. Vavuranakis M, Kalogeras K, Tousoulis T. Successful transcatheter aortic valve implantation of a low-profile last-generation aortic bioprosthesis in a patient with coarctation of the aorta. Can J Cardiol 2016; 32: 1575.e5-1575.e7.

9. Schramm R, Kupatt C, Becker C, Bombien R, Reichart B, Sodian R, Schmitz C. Transcatheter aortic valve implantation in aortic coarctation. Thorac Cardiovasc Surg 2013; 61: 336-339.

10. Panoulas VF, Montorfano M, Figini F, Spangnolo P, Contri R, Giustino G, Agricola E, Franco A, Latib A, Colombo A. Unanticipated pseudocoarctation highlights the importance of visualizing aortic arch anatomy before transfemoral trans catheter aortic valve implantation. Circ Cardiovasc Interv 2014; 7: 631-633. 